\title{
ANALYZING THE EFFECTIVENESS OF PUBLIC SPACES ON SOCIABILITY POTENTIAL OF CITIES: CASE STUDY OF NOBAHAR STREET, KERMANSHAH, IRAN
}

\author{
PEYMAN AMIRIPARYAN, CHRISTA REICHER \& ZOHREH KIANI \\ RWTH Aachen University, Faculty of Architecture, Germany
}

\begin{abstract}
The street as the pervasive and accessible urban public realm has considerable effects on the sociability potential of cities due to its multidimensional nature, embodying a range of activities from transportation, shopping, walking, and sitting to an urban space letting citizens experience and share social moments together. Hence, the street, by having a dynamic and pervasiveness characteristic, affects and promotes the sociability potential of cities and, subsequently, the quality of daily social life. This research, as a part of an ongoing PhD research at RWTH Achen University, Faculty of Architecture, aims to shed some light on the role of public space, and specifically the street, on the sociability potential of urban spaces. Hence, the purpose of this research is to evaluate the effectiveness level of Nobahar Street on social indicators of space as one of the densest streets in Kermanshah city, Iran. To achieve this purpose, a quantitative research method is assigned to realize this relation in three steps including library research to review the literature of the issue and to assign the indicators of the questionnaire as the second step of the research (data collection). The questionnaire was distributed among 120 citizens from different age groups and different genders, and, finally, in the third step of the research, the gathered data were analyzed by SPSS software. The results of the software show there is a strong relationship between Nobahar Street and its effects on social indicators assigned in the questionnaire.
\end{abstract}

Keywords: public space, sociability potential, social interactions, sense of vitality, personal and social identity, collective memory, sense of community, sense of invitation; social safety.

\section{INTRODUCTION}

This paper is a part of an ongoing doctoral thesis at the RWTH Aachen University focusing on the role of public spaces and especially streets on social indicators of urban spaces. Hence, this research is not based on a generalizability approach, but it is the initial part of a doctoral project aiming to analyze the effectiveness level of emerging public spaces on social indicators of urban space in Kermanshah, Iran. Public space has an intricate and multidimensional meaning and can be defined in different disciplines of the Social Sciences in different ways. Thus, each discipline defines public spaces on the basis of its own preferences and concerns. To achieve a proper realization of public spaces, a wide understanding regarding the term of public space is needed in order to present a comprehensive interpretation and definition of public space.

Since the 1980s, public spaces have witnessed a Renaissance in a way that they have increasingly become a key part of many regenerations and development urban policies worldwide with far-reaching impacts on how the resulting places are perceived and used [1], [2]. This noticeable development began as a consequence of many researchers focused on the significance of different models of public spaces on city structure, including streets, squares, parks, restaurants, cafes as began with Jacobs [3] to up the following studies in recent years. For example, Jacob's point about the role of street as public spaces explains the importance of the issue when she said: Streets and their sidewalks, the main public places of a city, are its most vital organs which can affect people's understanding about a city. 


\section{PUBLIC SPACE DEFINITIONS}

As a study done for the United Nation, namely Habitat III, Public Space [4] Public space is all places publicly owned or of public use, accessible and enjoyable by all for free and without profit motives such as streets, open spaces, and public facilities. Similarly, Carr et al. [5] explain "We define public spaces as open, publicly accessible places where people go for group or individual activities. Public spaces share common ingredients, and generally contain public amenities such as paving or lawn, benches, and water; physical and visual elements...that support activities. Whether planned or found, they are usually open and accessible to the public". In addition, they identify eleven types of public spaces such as public parks, squares, plazas, memorials, markets, streets, playgrounds, community open spaces, greenways, parkways, atrium/indoor marketplaces, found spaces/everyday spaces and waterfronts.

Carmona's study about public space [6] has a similar viewpoint stressing free accessibility to public spaces, public space relates to all those parts of the built and natural environment where the public has free access. It (public space) encompasses all the streets, squares and other rights of way, whether predominantly in residential, commercial or community/civic uses; the open spaces and parks; and the "public/private" spaces where public access is unrestricted. By emphasizing on the role of accessibility, Madanipour [7] defines public space as a space that allows all the people to have access to it and the activities within it, which is controlled by a public agency and which is provided and managed in the public interest, and not controlled by private individuals or organized and hence is open to the public [8].

Public spaces in the city are collective territories which limits are exactly defined (i.e. by buildings, gardens, streets) and they are well accessible (i.e. by different streets, alleys, stairs or parks). In this sense, they are places which are close and open at the same time and invites for a stay as also to traverse [9]. Besides accessibility, some studies underline another feature affecting the quality of public spaces namely, visibility. Public spaces are all the parts of the urban fabric to which the public has physical and visual access. Thus, it extends from the streets, parks, and squares of a town or city into the buildings which enclose and line them [10].

In these studies, the authors mostly consider the physical dimensions of public spaces and the feature of accessibility and visibility, while there is a strong interwoven relationship between accessibility, visibility and social dimensions of public spaces. Take the study by Korosec-Serfaty [9] as an example, as she believes the accessibility of public spaces for all facilitate social diversity, social behaviors, and social interactions. On the other study, Sharon [11] explains that public spaces are the physical areas and the tools for regulating the perspective of social life and interact with such spaces in the cities all the time. Empowering social interactions through free accessibility to public spaces is obvious as Tibbalds [10] believes "the public realm, in my view, is the most important part of our towns and cities... where the greatest amount of human contacts and interactions take place", and Walzer [12] expresses that "the public space is the space where we share with strangers, people who are not our relatives, friends, or work associates and we share our moments and activities with others". As for sharing activities in public spaces, Gehl [13] as one of the most influential researchers explains that public spaces facilitate the realization of activities and other citizenship interactions and similarly, Oldenburg [14] emphasizes that in third places in contrast to first places (home) and second places (work) people gather, hang out, informally interact, put aside their concerns and simply enjoy the company and conversations around them. Third spaces like the public places are neutral ground where people can gather and interact host the regular, voluntary, informal, and happily anticipated gatherings of 
individuals beyond the realms of home and work. Ray also explains that beer gardens, main streets, pubs, cafes, coffeehouses, post offices, and other third places are the heart of a community's social vitality.

Given a wide range of titles naming public space, including public places, public areas, public realms, and even third spaces, in this research given the commonality of the all definitions, the term of "public spaces" as an agglomeration of the definitions are utilized in this paper. Overall, as can be summarized from the general definitions presented by practitioners and experts, and particularly architects and urban designers, public space is a space where people can get access to it easily and freely, and all the social strata take advantage of it equally.

In terms of diversity, public spaces involve people from a vast range of social strata, including gender, age, ethnicity, sexuality, (dis)ability, social class, [15]. From the view of ownership, public spaces have two different origins, private and public ownership, and in terms of construction and development there are other categories such as governmental-based and private-based, and as for the form and essence, they are categorized into two open or closed, natural or the built public spaces.

\section{SOCIABILITY NATURE OF PUBLIC SPACE}

The Term of public space has two physical and social aspects therefore, understanding and analyzing public space require studying both physical and social aspects simultaneously and realizing the dynamic relationships between them. Public space as a material space could be recognized from its spatial form and order, while the social dimension of public space deals with people, their behaviors and activities, supporting the public life of society [16].

Due to the social potential of public space many researchers, urban designers, and planners emphasize the importance of public space where social interactions and the daily experience of urban life take place and affect directly the quality of social life. For example, Mean and Tims [17] believe public spaces, including high street markets, shopping precincts, community centers, parks, playgrounds, and neighborhood spaces in residential areas act as a "self-organizing public service", and as a shared resource in which social experiences and values are created in ways that are impossible in our private lives alone and subsequently can have a positive impact on social life. They also believe places can provide opportunities for social interaction, social mixing, and social inclusion, and can facilitate the development of community ties. Likewise, Orum and Neal [8] underline that public spaces provide sites and conditions for social interactions constituting public life: civic. Whyte [18] in a field study in the book titled as follow: The Social Life of Small Urban Spaces, shows that users appeared to take pleasure in the act of people watching and enjoyed listening to water features such as plaza fountains. Watching and experiencing the activities of others in public spaces have such a stimulating effect that can gather people around each other. As a common saying in Scandinavia, people come where people are [19] meaning public areas also enable people to connect with others to affiliate in some way with other people [5]. As the same research Paasch [20] in Livable Dimension of Public Spaces believes, a social public space affects evening use and street life. People can come together to meet, volunteer and cooperate. Furthermore, diversity and a sense of community are related qualities of sociability in urban space.

Considering the aim of this research, to evaluate the role of public space on the sociability potential of cities, some general qualities of public spaces are explained based on comprehensive research by Carmona et al. [21] and Carr et al. [5] explaining the reason behind choosing the indicators of the questionnaire in this research. 
Carmona et al. [21] introduces eleven positive aspects of successful public spaces consisting of environmental to social aspects, such as cleanness, accessibility, inclusion, viability, attractiveness, and safety. Socially, attractiveness addresses visually pleasing public space and its role on the level of invitation, while inclusive and vitality consider well coming and diversity of uses (fostering interactions) respectively. Similarly, Carr et al. [5] emphasizes that public spaces should have three characteristics to be a successful public space, including responsivity to serve the needs of users such as comfort, relaxation, active and passive engagement (making social interaction), and discovery (making social bonds), and they must be democratic, to protect the right of user groups, and finally they should be Meaningful.

\subsection{Assigning the indicators of the questionnaire}

Given the above explanation and those indicators assigned as the characteristics of public spaces socially and the aim of this research, the below seven indicators are assigned in the questionnaire as an agglomeration of all features highlighting social effects of public spaces, namely social interactions, creating and enhancing the sense of vitality, making personal and public identity, creating collective memory, creating a sense of community, promoting the sense of invitation (all ages and genders) and promoting social safety.

\subsubsection{Social interactions}

The main function of public spaces is the development of social interactions among citizens as Orum and Neal believe such interactions are vital for the life of a city as well as the life of society in general [8].

\subsubsection{Creating and enhancing the sense of vitality}

Vitality is one of the most important indicators of successful public space leading to an improvement in the quality of social life, as Gehl and Gemzøe [22] and Mehta [23] provide further evidence that the quality of public space is linked to social use and liveliness. Furthermore, Tawil et al. [24] identifies the vitality as one of the performance dimensions of urban design and describes it as the degree to which the form of places supports the functions, biological requirements, and capabilities of human beings.

\subsubsection{Making personal and public identity}

Identity is not an innate quality of man, and it is made by sharing experiences and activities within a society, [25]. Intrinsically, public spaces are not able to produce identity, but as a container provides the possibility of realization of personal and public identity. They act as social realms to facilitate social interactions and social bonds among people, and among a variety of shared experiences and feelings, a kind of identity towards others will be shaped.

\subsubsection{Creating collective memory}

Collective memory is shaped while spending time with others and engaging with their activities passively or actively, and public space has the potential to facilitate happening these activities.

\subsubsection{Creating a sense of community}

Sense of community means a sense of belonging and experiencing the community, made by mixing with others, as Orum and Neal [8] explain the close social bonds we develop in public spaces provide a sense of belonging and security. The interest in the broader built environment and its influence on the sense of community is gaining momentum nowadays, 
as studies prove that perceived the quality of public open spaces and the shopping amenities have a positive and significant association with a sense of community [26].

\subsubsection{Promoting the sense of invitation}

One of the most important functional features of public spaces is the promotion of the invitation sense by providing people's needs. Making an inviting environment can act as a gathering place to attract public as Whyte's study of the public squares [18] in New York in the 1970s and 1980s reveals people like to go where others are. These social realms embody various social groups, regardless of the age, religion, gender, ethnicity and make a public and inclusive territory for all. As an inclusive feature, public spaces act as a melting point for all social groups, including the marginal, the forgotten, the silent, Badshah [27], and undesirable social minority groups like informal vendors, street people with different abilities like women, children, elderly, and others marginalized in the community [25].

\subsubsection{Safety}

The most fundamental and vital characteristic of public space embodying the public is safety, and it is crucial if we hope people embrace city space. The bedrock attribute of a successful city district is that a person must feel personally safe and secure on the street among all these strangers [3]. According to research, making safety in public space embodies a vast range of environmental features and social surveillance from a good city layout [19] to a sensory attribute amongst attractiveness of public spaces [28], [29] and as social surveillance.

\section{STREETS: THE MOST PERVASIVE PUBLIC SPACE}

Undoubtedly, streets as pervasive public spaces empower the sociability potential of cities in order to improve the quality of social life. The effect of streets is such significance in the city that Jacobs [3] believes streets and their sidewalks, are its most vital organ and think of a city and what comes to mind? Is its streets! If city streets look interesting, the city looks interesting, if they look dull, the city looks dull. Today, the importance of streets as the social realms in cities are under the attention of many urban planners, urban designers, and architects, and decision-makers, hence an ever-increasing policy, focusing on the development of the quality of street life in urban morphology has begun during recent decades. Owing to the significance of street on city life, many cities like New York and Paris have developed streets as public spaces which not only act as major thoroughfares, but also as engaging hot spots for social interactions, and in doing so foster a sense of community and social connectedness [30]. One of the main reasons behind such attention lies in the hands of the multi-functional nature of streets supporting a range of activities. Wood et al. [31] believe that a street which has the potential to improve walkability and support social capital can bring about positive interactions in a neighborhood. Streets are increasingly expected to provide a focus for community life, to make a distinctive identity for an area, to make safe spaces for all, to be vibrant and vital at all times, and at the same time provide an efficient corridor for public and private transport [6].

\section{RESEARCH METHODOLOGY}

The methodology of this paper is a quantitative method aiming to study the effectiveness level of Nobahar Street on social indicators of space in which the results are quantitative and measurable as for the theory and the assumption of the research. The research method can be explained in three steps, firstly the library research to study the literature of the paper, secondly, data gathering via devising a questionnaire and thirdly analyzing data by SPSS software. 
In fact, the assumption of the research sheds light on the research method that Nobahar Street has considerable effects on social indicators of the city such as social interactions, a sense of vitality, personal and social identity, collective memory, sense of community, sense of invitation, and social security. Therefore, in the library study, the aim aside from reviewing the literature of the issue is extracting the relevant social indicators of the questionnaire as an agglomeration of different social features of public spaces which can affect the sociability potential of cities. In the second part, the extracted indicators are used in devising a questionnaire as a tool of data collection (a quantitative tool) and they are distributed among 120 citizens from different genders and age groups (18-75 years old) randomly as a diverse statistical population in a period of 30 days from the May 2019. It must be mentioned, although expanding the statistical population in a longer period in different moths can support the validity of the assumption of the research, as the social characteristic of this research the permanent, studying another time period must be taken under study according to social changes, and also this is the initial findings of a more ongoing comprehensive research. Finally, the result of the questionnaires are analyzed with SPSS software and the results show there is a coherent and meaningful relationship between Nobahar Street and empowering social potentials of space. The results of the descriptive statistics show the amplitude oscillations, the mean and standard deviation of the indicators. The Pearson correlation also the correlation level of indicators towards Nobahar Street.

\subsection{Research background}

As comprehensive research, this part of the research is extracted, reviewed and rewritten according to an article [32] explaining a short review about the background of the research ranging from 1980 to 2014. Whyte [18] in the Street Life project studies the failure of many urban spaces developed over 50 years, and the results of his research show that the street attractiveness for people seriously is affected by the presence of others proving the vital role of people in the social life of cities. In 1982, Appleyard [33] came with a report in Livable Streets analyzing the role of traffic on social interactions. Jacobs [34] in Great Streets stresses the influence of good streets on improving social interactions, and she emphasizes the role of site observation, instead of a superficial view of blueprints and its effect on the process of decision-making. Gehl [19] as another researcher puts his concentration on an extensive observation to understand the mutual relationship between the built environment and human behavior and their effects on vitality of social life in many cities including Copenhagen, Melbourne, and New York. From a phenomenological and behavioral perspective, Stevens [35] re-evaluates and extends the model of Francis et al. [26] and his five urban elements via a concentration on systematic observation through photography and recording behavioral maps. Mehta [23] addresses the role of stationary social interactions in local streets and the needs of users using a behavioral mapping and interviewing with users. His paper concentrates on understanding the special features in the environment supporting social interactions on commercial zones of neighborhoods. As some relevant research accomplished in Kermanshah, Bakhtiari Manesh and Bakhtiari Manesh [36] has a research about the role of the built environment on the vitality of Nobahar Street in Kermanshah, and she comes with three findings that three factors including being protective, comfortable and pleasant lead in the vitality of Nobahar Street. Mansouri and Jahanbakhsh [37] investigate to understand the role of urban fabric, function, and meaning of Modarres Street in Kermanshah on sociability and vitality, and they conclude that pedestrian, non-verbal relations, and the time and spacebased social interactions have the most effects on the sociability potential of Modarres Street and social interactions. As the other research, Farazmand and Sahizadeh [38] in their research 
in Kermanshah in the area of Parking Shahrdari study to understand the effectiveness level of the case on social interactions via a quantitative research method including a questionnaire, and their findings show the case study does not have enough capacity to empower social interactions.

\subsection{Nobahar Street}

This paper is the preliminary results of a Ph.D. thesis proceeding at the University of RWTH, Architecture Department, focusing on analyzing the influence of emerging public spaces on the sociability potential of urban spaces in Kermanshah, and as a case study, this paper focuses on Nobahar Street as one of the densest urban zones. Kermanshah city is the center of Kermanshah province, located $252 \mathrm{~km}$ from Tehran in the west of Iran, and according to the 2015 census, its population is 1,083,833 [39]. Nobahar Street is located in the central part of Kermanshah linking Si Metri Dovom Street and Nobahar Street (Fig. 1(a)) embodying a high-density urban texture, including residential and commercial spaces, public services and act as a dynamic walkable environment. During the recent decade, due to the centrality of the street socially and economically in Kermanshah, the public and private sector have invested dramatically in this street. For example, many public services such as public transportation, green spaces and different facilities like urban furniture and toilets have been made by the $1^{\text {st }}$ Municipality and, in addition, the investment of the private sector on commercialization of the urban spaces to stores, cafes, and restaurants have changed the appearance and function of Nobahar Street. In regard to the spatial analysis accomplished by Depth Map software and field observations, Nobahar Street is one of the three most integrated urban spaces in Kermanshah which has a high level of accessibility, connectivity, and permeability to the adjacent neighborhood (Fig. 1(b)). Furthermore, urban statistics [39] anticipate that 22 Bahman neighborhood (embodying Nobahar Street) will experience the highest rate of population growth up to 73,428 residents in 2021 compared with the other 135 neighborhoods in Kermanshah. While it should not be overlooked to explain that 22 Bahman as one neighborhood out of six in the 1st District Municipality in Kermanshah is the sixth most populous district among eight districts in Kermanshah to 97037 residents [39]. Likewise, according to urban statistics [36], the adjacent neighborhood of Nobahar Street (22Bahman) owns the highest rate of multistory residential buildings (56\%) compared with the other 135 neighborhoods in Kermanshah. Commercialization of the urban spaces is another characteristic of 22 Bahman as well, which has been affected by the socio-spatial influence of the Nobahar Street, as the red spots in Fig. 1(c) show the status quo of commercial spaces in Kermanshah [39] and Nobahar Street located in the high-density commercial zone. Nobahar Street beyond its urban function acts as an urban zone, improving the social potential of the neighborhood and also the quality of social life indicators such as safety, social interactions, a sense of vitality, and personal and collective memory.

\subsection{Questionnaire}

One of the most common quantitative research tools in survey research is a questionnaire to be used in the process of data collection and consists of a set of targeted questions in order to measure people's perspectives about a subject. Likewise, using a questionnaire is due to the complexity and the impossibility of studying the extensive statistical population. Hence, the researcher examines the research variables by selecting a sample group that represents the statistical population. 


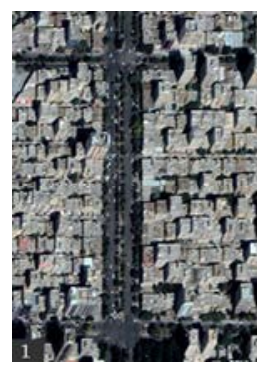

(a)



(b)

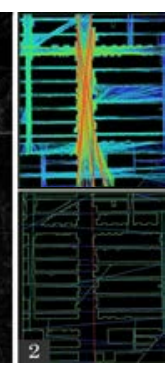

(c)

Figure 1: Nobahar Street, Kermanshah, Iran. (Source: Google map. Figure - Depth Map Analysis, Integration - 22 Bahman, Commercialization Zones.)

In this research the questionnaire is devised based on seven indicators resulted from the literature review, including social interactions, creating and enhancing the sense of vitality, making personal and public identity, creating a collective memory, and a sense of community, promoting the sense of invitation, and social safety. The questionnaire was distributed among 120 citizens from different sexes (male and female) and age groups from 18-75 years old randomly. All interviewers are trained to explain the questionnaire to interviewees not biased, and finally, the answer sheets are analyzed by SPSS software as follows.

\subsection{Data descriptive survey}

Table 1 depicts the results obtained from the questionnaire and from left to right, the first, second and third columns belong to the indicators, the number of correct answer sheets and the highest and the lowest measures respectively, and fifth and sixth columns are mean and the standard deviation in turn. The standard deviation measures the dispersion of a dataset relative to its mean and is calculated as the square root of the variance. It is calculated as the square root of variance by determining the variation between each data point relative to the mean. If the data points are further from the mean, there is a higher deviation within the data set; thus, the more spread out the data, the higher the standard deviation [40], also, the fewer differences between the Max and Min quantities the less standard deviation and vice versa. As an explanation, in this table, the relationship between Maximum and Minimum quantities shows a different level of effectiveness of Nobahar Street on the social indicators based on interviewees' viewpoints. Although the maximum quantities are close to each other, the minimum quantities are different, for instance. In the mean column, there are various measures from the highest level, such as social interaction (4.43/5) and sense of invitation $(4.00 / 5)$ to the lowest quantities, including personal and public identity $(3.16 / 5)$ and sense of community (2.57/5). The effectiveness level of Nobahar Street on social indicators can be evaluated based on standard deviation. It means the more tendency towards 0 the more effective level of Nobahar Street on a specific indicator and vice versa. Accordingly, Nobahar Street has the highest social effect on the sense of invitation with 0.226 and safety and social interaction with 0.423 and 0.497 in the next steps, while it has the lowest effect on personal and public identity with 1.262. In fact, Mean explains the general average of every indicator based on the number of interviewees, while Sd explains the number of fluctuations between the highest and the lowest indicators. 
Table 1: The relative mean of the quantities extracted based on the priorities determined in the questionnaire.

\begin{tabular}{|l|c|c|c|c|c|}
\hline \multicolumn{7}{|c|}{ Descriptive statistics } \\
\hline Indicators & $\mathrm{N}$ & Minimum & Maximum & Mean & $\begin{array}{c}\text { Standard } \\
\text { deviation }\end{array}$ \\
\hline Social interactions & 119 & 4 & 5 & 4.43 & 0.497 \\
\hline Sense of vitality & 119 & 2 & 5 & 3.76 & 0.909 \\
\hline Personal and public identity & 119 & 1 & 5 & 3.16 & 1.262 \\
\hline Collective memory & 119 & 2 & 5 & 3.29 & 1.174 \\
\hline Sense of community & 119 & 1 & 4 & 2.57 & 0.962 \\
\hline sense of invitation & 119 & 3 & 5 & 4.00 & 0.225 \\
\hline Safety & 119 & 2 & 5 & 3.92 & 0.423 \\
\hline
\end{tabular}

\subsection{Evaluation of the effectiveness level of Nobahar Street on indicators}

One-Sample Test is used to describe the results of the descriptive information in Table 3. Mean 3.01 confirms the mean level of Nobahar Street effectiveness on the indicators used in the research. Furthermore, the results illustrated in Table 3 show that the significance level of the indicators is 0 indicating the differences between the indicators statistically is meaningful, and conceptually it means that the indicators are assigned based on a semantic cohesion (Table 3), and the Sd shows an acceptable trend toward 0.00 with 0.2605 .

Table 2: The results from social indicators.

\begin{tabular}{|c|c|c|c|c|}
\hline & N Sample size & Mean & Standard deviation & Standard error mean \\
\hline Indicators & 119 & 3.01 & 0.2605 & 0.0238 \\
\hline
\end{tabular}

Table 3: Significance level-one-sample statistics.

\begin{tabular}{|c|c|c|c|c|c|c|}
\hline & \multicolumn{6}{|c|}{ Test value $=0$} \\
\hline & \multirow[t]{2}{*}{ Statistics } & \multirow{2}{*}{$\begin{array}{l}\text { Degree of } \\
\text { freedom }\end{array}$} & \multirow{2}{*}{$\begin{array}{c}\text { Significance } \\
\text { level }\end{array}$} & \multirow{2}{*}{$\begin{array}{c}\text { Mean } \\
\text { difference }\end{array}$} & \multicolumn{2}{|c|}{$\begin{array}{c}95 \% \text { Confidence } \\
\text { interval of the difference }\end{array}$} \\
\hline & & & & & Low limit & High limit \\
\hline Indicators & 126.273 & 118 & 0.000 & 3.01 & 2.96 & 3.06 \\
\hline
\end{tabular}

\subsection{Pearson correlation coefficient}

The Pearson correlation coefficient is a measure of the strength of a linear association between two variables and is denoted by r. Basically, a Pearson correlation attempts to draw a line of best fit through the data of two variables, and the Pearson correlation coefficient, $r$, indicates how far away all these data points are in this line of best fit. The Pearson correlation coefficient, $r$, can take a range of values from +1 to -1 . A value of 0 indicates that there is no association between the two variables, and greater than 0 indicates a positive association; that is, as the value of one variable increases, so does the value of the other variable. A value less than 0 indicates a negative association; that is, as the value of one variable increases, the value of the other variable decreases [41]. Thus, Table 4 presents the results obtained from Pearson correlation analysis, the correlation coefficient and the relevant $\mathrm{p}$-value. $\mathrm{R}$ is obtained 0.650 with significance coefficient 0.000 . Based on the results, the measure obtained 
explains the significant correlation between the impact of Nobahar Street and the social indicators of the questionnaire.

Table 4: The extent of the correlation coefficient with the sustainability indicator.

\begin{tabular}{|c|l|c|c|}
\hline \multicolumn{3}{|c|}{ Correlation } \\
\hline \multirow{3}{*}{ Nobahar Street } & Nobahar Street & Indicators \\
\cline { 2 - 4 } & Searson Correlation & 1 & $0.650^{* *}$ \\
\cline { 2 - 4 } & Number & 119 & 0.000 \\
\hline
\end{tabular}

6 CONCLUSION

Nobahar Street in Kermanshah is one of the densest urban zones based on a spatial analysis and field study. Beyond the formal function of Nobahar Street, the socio-spatial effects of the street has expanded into the adjacent neighborhood as a dynamic flow through a high level of permeability and depth, also a continuous connection to the adjacent urban context, an unlimited accessibility and the highest level of visibility expanding a deep visibility via straight and cross side streets. In this research, in order to analyze the effectiveness level of Nobahar Street on the sociability potential of the urban space, quantitative research is assigned that aside from library research, the relationship between Nobahar Street and social indicators are analyzed by SPSS. The results of the questionnaire show the Mean of 4.43-5 of people's viewpoints believe Nobahar Street has the highest level of social effect on social interaction, and in the following steps sense of invitation, safety, vitality, collective memory, identity and sense of community with the lowest measure with 2.57. Standard deviation explains that, contrary to the Mean, Nobahar Street has the highest social effect on the sense of invitation with 0.225 and then on safety and social interaction with 0.423 and 0.477 in turns and in the lowest level identity with 1.262. The One-sample test table depicts the mean of all indicators is 3.01/5, meaning Nobahar Street has a noticeable effect on the sociability potential of the neighborhood. One-sample test table also shows the total standard deviation is 0.2605 describing the interviewees' answers proving that the deviation of indicators is limited and there is a strong semantic meaning between them. There is also a strong collaboration between indicators and Nobahar street up to $0.650 / 1$, explaining to what extent Nobahar Street can affect sociability indicators.

\section{REFERENCES}

[1] Crowhurst Lennard, S.H. \& Lennard, H.L., Livable Cities Observed: A Source Book of Images and Ideas for City Officials, Community Leaders, Architects, Planners and All Others Committed to Making Their Cities Liveable, Gondolier Press, 1995.

[2] Corbett, N., Transforming Cities: Revival in the Square, Riba Publications, 2004.

[3] Jacobs, J., The Death and Life of Great American Cities, Vintage: New York, 1992.

[4] Habitat III Issue Papers, Public Space. United Nation conference housing and sustainable development. October 2016, Quito: New York, 2015.

[5] Carr, S., Stephen, C., Francis, M., Rivlin, L.G. \& Stone, A.M., Public Space, Cambridge University Press, 1992.

[6] Carmona, M., Heath, T., Oc, T. \& Tiesdell, S., Public Places-Urban Spaces, Routledge, 2012.

[7] Madanipour, A., Design of Urban Space: An Inquiry into a Socio-Spatial Process, Wiley: Chichester, 1996. 
[8] Orum, A.M. \& Neal, Z.P., Common Ground? Readings and Reflections on Public Space, Routledge, 2009.

[9] Korosec-Serfaty, P., Öffentliche Plätze und Freiräume. Ökologische Psychologie: Ein Handbuch in Schlüsselbegriffen, Studienausgabe, Beltz Verlag: Weinheim, 532 pp. 1996.

[10] Tibbalds, F., Making People-Friendly Towns: Improving the Public Environment in Towns and Cities, Taylor \& Francis, 2012.

[11] Sharon, Z., The Cultures of Cities, Oxford: Blackwell, 1995.

[12] Walzer, M., Public Space-Pleasures and Costs of Urbanity, Dissent, 1986.

[13] Gehl, J., Life between Buildings, Using Public Space, Island Press: Copenhagen, 1971.

[14] Oldenburg, R. ed., Celebrating the Third Place: Inspiring Stories about the Great Good Places at the Heart of our Communities, Da Capo Press, 2001.

[15] Holland, C., Clark, A., Katz, J. \& Peace, S., Social Interactions in Urban Public Places, Policy Press, 2007.

[16] Widiyastuti, D., Transformation of Public Space: Social and Spatial Changes: A Case Study of Yogyakarta Special Province, Indonesia, Dortmund University, 2013.

[17] Mean, M. \& Tims, C., People Make Places: Growing the Public Life of Cities, Demos, 2005.

[18] Whyte, W.H., The Social Life of Small Urban Spaces, Project for Public Spaces Inc, 1980.

[19] Gehl, J., Cities for People, Island Press, 2013.

[20] Paasch, S., Livable dimensions of public spaces. Thesis, Faculty of Science, Department of Psychology: Technische Universität Dresden, 1988.

[21] Carmona, M., Heath, T., Oc, T. \& Tiesdell, S., Urban Spaces-Public Places: The Dimensions of Urban Design, Routledge, 2012.

[22] Gehl, J. \& Gemzøe, L., Public Spaces-Public Life, The Danish Architectural Press, 2004.

[23] Mehta, V., The Street: A Quintessential Social Public Space, Routledge: Abingdon and New York, 2013.

[24] Tawil, M.F., Reicher, C., Jafari, M. \& Baeumer, K., Assessment of public space efficiency in relation to spatial development in Amman: Exploring indicators to sustainable models of future city life. Journal of Sustainable Development, 9(3), 2016.

[25] Lynch, K., The Image of the City, MIT Press, 1960.

[26] Francis, J., Giles-Corti, B., Wood, L. \& Knuiman, M., Creating sense of community: The role of public space. Journal of Environmental Psychology, 32(4), pp. 401-409, 2012.

[27] Badshah, A.A., Our Urban Future: New Paradigms for Equity and Sustainability, London and New Jersey, 1996.

[28] Childs, M.C., Squares: A Public Place Design Guide for Urbanists, UNM Press, 2006.

[29] Marcus, C.C. \& Francis, C., People Places: Design Guidelines for Urban Open Space, Second Review end edition, John Wiley \& Sons, 1997.

[30] Ng, S., Lau, W., Brown, F., Tam, E., Lao, M. \& Booth, V., Walkable city, living streets, 2003. RACGP. https://civic-exchange.org. Accessed on: Oct 2012.

[31] Wood, L., Shannon, T., Bulsara, M., Pikora, T., McCormack, G. \& Giles-Corti, B., The anatomy of the safe and social suburb: an exploratory study of the built environment, social capital and residents' perceptions of safety. Health \& Place, 14(1), pp. 15-31, 2008. 
[32] Dousti, F. \& Mostafa Behzadfar, A.V., A new reading of sociable public spaces: The Nexus between urban design and microsociology. Armanshahr Architecture \& Urban Development, 11(22), pp. 39-49, 2018.

[33] Appleyard, D., Livable Streets, University of California Press, 1981.

[34] Jacobs, A.B., Great Streets, MIT Press, 1993.

[35] Stevens, Q., The shape of urban experience: A re-evaluation of Lynch's five elements. Environment and Planning B: Planning and Design, 33(6), pp. 803-823, 2006.

[36] Bakhtiari Manesh, E. \& Bakhtiari Manesh, M., Investigating the physical conditions and factors that enhance the vitality of urban spaces (Nobahar Street). Fourth International Conference on Modern Research in Civil Engineering, Architecture, Urban and Environmental Managemen 2019, Karaj, Iran: University of Applied Science and Technology.

[37] Mansouri, S.J. \& Jahanbakhsh, H., Factors affecting the measurement of promoting social interaction and socialization in the Urban Space (Modares Street, Kermanshah). Iranian Association of Architecture \& Urbanism, 7(11), 2017.

[38] Farazmand, R. \& Sahizadeh M., An analysis of the components affecting vivacity from the viewpoint of social interaction in evaluating the performance of urban public spaces. Haft Hesar, 2(6), pp. 29-42, 2014.

[39] Results of Population and Housing Census in Kermanshah. Kermanshah Plan and Budget Organization, 2015.

[40] Investopedia. www.investopedia.com. Accessed on: July 2019.

[41] Laerd Statistics. https://statistics.laerd.com. Accessed on: June 2019. 